\title{
Infantile amnesia: A neurogenic hypothesis
}

\author{
Sheena A. Josselyn ${ }^{1,2,3,4}$ and Paul W. Frankland ${ }^{1,2,3}$ \\ ${ }^{1}$ Program in Neurosciences \& Mental Health, The Hospital for Sick Children, Toronto, Canada M5G 1X8; ${ }^{2}$ Department of Physiology, \\ University of Toronto, Toronto, Canada M5S 1A8; ${ }^{3}$ Institute of Medical Science, University of Toronto, Toronto, Canada M5S 1 A8
}

\begin{abstract}
In the late 19th Century, Sigmund Freud described the phenomenon in which people are unable to recall events from early childhood as infantile amnesia. Although universally observed, infantile amnesia is a paradox; adults have surprisingly few memories of early childhood despite the seemingly exuberant learning capacity of young children. How can these findings be reconciled? The mechanisms underlying this form of amnesia are the subject of much debate. Psychological/cognitive theories assert that the ability to maintain detailed, declarative-like memories in the long term correlates with the development of language, theory of mind, and/or sense of "self." However, the finding that experimental animals also show infantile amnesia suggests that this phenomenon cannot be explained fully in purely human terms. Biological explanations of infantile amnesia suggest that protracted postnatal development of key brain regions important for memory interferes with stable long-term memory storage, yet they do not clearly specify which particular aspects of brain maturation are causally related to infantile amnesia. Here, we propose a hypothesis of infantile amnesia that focuses on one specific aspect of postnatal brain development-the continued addition of new neurons to the hippocampus. Infants (humans, nonhuman primates, and rodents) exhibit high levels of hippocampal neurogenesis and an inability to form lasting memories. Interestingly, the decline of postnatal neurogenesis levels corresponds to the emergence of the ability to form stable long-term memory. We propose that high neurogenesis levels negatively regulate the ability to form enduring memories, most likely by replacing synaptic connections in preexisting hippocampal memory circuits.
\end{abstract}

We are the proud parents of a little girl who just turned $2 \mathrm{yr}$ of age. To celebrate this milestone, we threw a party with all the trimmings (Elmo birthday cards, presents, sparkly birthday hats, and a chocolate cake topped with two pink candles). When we dimmed the lights and lit the candles, the birthday girl burst into tears. This event seems permanently etched in our memories, and we can vividly recall many details of the not-so-happy birthday. Our daughter remembered parts of this event, too, at least for a day or two (the next day, she exclaimed "no candles" while shaking her head vigorously). Have we scarred our daughter for life? Perhaps. But if she is like the rest of us, she will not explicitly remember the "birthday candle incident" when she is an adult. This phenomenon, in which adults are unable to remember specific events from our first few years of life, was named infantile amnesia by Sigmund Freud over 100 yr ago (Freud 1900, 1914). What is particularly intriguing about this phenomenon is that adults have very few memories of early childhood despite the seemingly exuberant learning capacity of young children. How can these seemingly disparate observations be reconciled? Here, we outline a novel neurobiological hypothesis of infantile (or childhood) amnesia that proposes that the loss of memory in infants and children is due to high levels of postnatal neurogenesis in the hippocampus.

\section{Infantile amnesia-the phenomenon}

Adults have difficulty recalling memories of early childhood, even though very young children are capable of forming memories

Freud developed his theory of infantile amnesia based on the observation that his adult patients rarely recalled memories of their first years of life (before 6-8 yr of age) (Freud 1900, 1914). This an-

\footnotetext{
${ }^{4}$ Corresponding author

E-mail sheena.josselyn@sickkids.ca

Article is online at http://www.learnmem.org/cgi/doi/10.1101/lm.021311.110.
}

ecdotal evidence has been validated by over a century of empirical research, conducted across cultures using different techniques (Miles 1893; Henri and Henri 1895; Howe and Courage 1993; Nelson 1993; Peterson 2002; Wang 2003; Bauer 2006, 2007). Of course, much of the experimental evidence for infantile amnesia comes from retrospective studies (in which adults are asked to recall their first memories) which are laden with pitfalls and interpretive difficulties. Despite this, a strikingly similar pattern of results has emerged across these many studies: adults generally cannot remember events that occurred in the first 2-3 yr of life. In addition to this frank amnesia for early infancy, there is a second phase of infantile amnesia in which adults recall very few memories from ages 3-7 yr (Rubin 1982; Wetzler and Sweeney 1986; Rubin 2000; Peterson 2002). Therefore, infantile amnesia is not an all-or-none phenomenon, and there is no abrupt developmental transition from "no memory" to "memory." Instead, infantile amnesia describes the absence of memory for events occurring within the first $2-3$ yr of life and "spotty" memory for events occurring from 3-7 yr of age (Pillemer and White 1989; Bruce et al. 2005; Fig. 1).

Can infantile amnesia be attributed to normal forgetting? In adults, forgetting can be described as a linear function of the time since an event. Because there is a long delay between events acquired during infancy and potential recall in adulthood, it might be expected that these early life events are simply forgotten. To examine this, Rubin and colleagues sampled adults' memories across the life span (Rubin 1982, 2000; Peterson 2002). Subjects were given cue words (e.g., bicycle) and asked to provide a specific memory related to the cue word and estimate their age at the time of the event. The resulting distribution of memories clearly showed the two components of infantile amnesia (0-3 yr of age and 3-7 yr of age). Importantly, subjects reported far fewer memories for events that occurred between birth and 6-7 $\mathrm{yr}$ of age than would be predicted by simply extrapolating the adult forgetting curve (Wetzler and Sweeney 1986). Therefore, forgetting a 


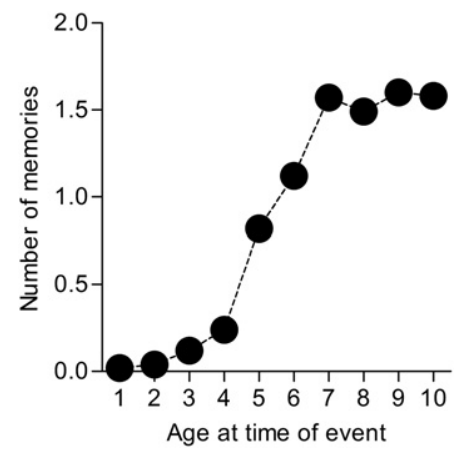

Figure 1. Infantile amnesia in humans. Distribution of autobiographical memories from the first decade of life showing two phases of infantile amnesia. Values (mean number of memories per yr) are approximate and based on Rubin and Schulkind (1997). Participants (20, 35, and 70 $\mathrm{yr}$ of age) reported very few memories before the age of three. The number of memories reported to have occurred from the ages of 3-7 $y r$ increased linearly and leveled off from 7-10 yr of age.

memory with the passage of time alone cannot explain infantile amnesia.

\section{Can infants form declarative memories?}

What types of memories are lost in infantile amnesia? In adult memory research, different theoretical distinctions have been proposed to delineate different types of memory; the two most common categories are declarative versus nondeclarative memory (Squire 1994) or explicit versus implicit memory (Graf and Schacter 1985). Implicit memory refers to the unconscious learning that is expressed by changes in task performance as the result of experience. Testing this type of memory does not require participants to verbally declare things. In contrast, declarative/explicit memory refers to the conscious recollection of facts and events. While many experiences during infancy implicitly impact later life (e.g., Hackman et al. 2010), infantile amnesia typically refers to the absence of declarative memories from this period.

The capacity to form and verbally recall declarative memories gradually emerges as an infant develops (from $\sim 24-36$ mo of age) (Eisenberg 1985; Peterson and McCabe 1987; Miller and Sperry 1988; Hudson 1991; McCabe and Peterson 1991; Hudson et al. 1992, 1995; Harley and Reese 1999; Peterson et al. 1999; Peterson 2002). For instance, 3-yr-old children accurately recount "important" life events (a trip to McDonald's) when prompted (Nelson and Gruendel 1981). Even in the absence of such prompting, children verbally recall specific event/autobiographical memories. For instance, Nelson eavesdropped on the "crib talk" (i.e., talking to oneself alone before sleep) of her 2.5-yr-old daughter, who clearly described a unique episode (buying a doll) that was not rehearsed with, or structured by, her parents (Nelson 1989; Harley and Reese 1999; Nelson and Fivush 2004). Together, these and other studies are remarkable in that they reveal that children form and verbally report event memories, yet these same memories are inaccessible when these children become adults. If these types of memories can be formed, what is their fate?

\section{Older children remember longer}

One predominant view is that, although children can learn and remember information for a short period of time, these memories are quickly forgotten or become otherwise inaccessible (Bauer 2007; Rovee-Collier and Cuevas 2009). That is, given equivalent levels of encoding, older infants remember for longer than youn- ger infants. Support for age-related changes in childhood forgetting derives from several findings. For instance, Rovee-Collier and colleagues showed that memory retention increases linearly with the age of the child at the time of training (Rovee-Collier 1997; Rovee-Collier and Cuevas 2009; Fig. 2). The absolute difference in retention was striking - although 2-mo-old infants exhibited memory that lasted $24 \mathrm{~h}, 18$-mo-old infants exhibited retention for as long as $13 \mathrm{wk}$. Because all infants were trained to the same criterion, the authors concluded that the age-related changes in memory retention were independent of possible differences in the original encoding of the information.

A similar pattern of results-that older children remember for longer than younger children-has been observed across several tasks, including deferred imitation (Barr et al. 1996; Herbert and Hayne 2000; Carver and Bauer 2001; Bauer 2007), visual paired comparison (Fantz 1956; Herbert and Hayne 2000; Morgan and Hayne 2006a,b, 2011), and autobiographical memory (Ornstein et al. 1997; van Abbema and Bauer 2005; Tustin and Hayne 2010) tests. Together, these findings converge to show that, although young children can acquire memories, they forget faster than older children. This faster forgetting is independent of the task used to measure memory and is argued to be independent of differences in memory encoding. Intriguingly, rodents exhibit a strikingly similar age-dependent amnesia.

\section{Infantile amnesia is recapitulated in rodent species}

Some of the earliest studies of infantile amnesia in rodents were conducted by Campbell and colleagues, starting in the 1960s (Campbell and Campbell 1962; Campbell et al. 1968, 1974; Coulter et al. 1976; Stehouwer and Campbell 1980). These researchers trained rats of different ages (18- to 100-d old) in an aversively motivated place discrimination task and tested memory retention 0, 7, 21, or 42 d later (Campbell and Campbell 1962). All groups of rats showed perfect (or near perfect) retention if tested immediately following training, indicating that rats of all ages

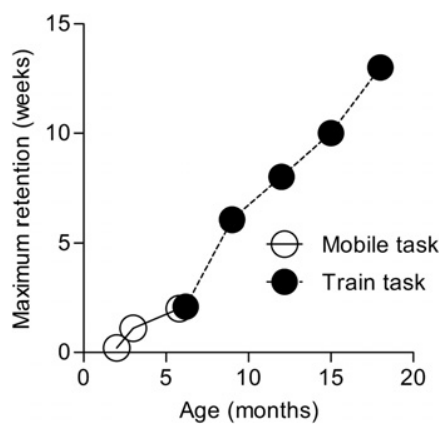

Figure 2. Memory retention increases gradually with age of children. Rovee-Collier and colleagues used a mobile conjugate reinforcement task (in which infants learn to kick their foot in order to rotate an overhead mobile) to assess learning and memory in young infants (2- to 7-mo-olds) and a variant of this task (in which infants learn to press a lever to move a toy train) in older infants (6- to 18-mo-olds). These researchers argue that these tasks also tap into declarative memory in infants (Rovee-Collier 1997). When infants of different ages (ranging from 2 to $18 \mathrm{mo}$ ) are trained to the same criterion in the mobile (open circles) or train (closed circles) task, the duration of memory retention increases linearly as a function of age. Immediate retention was equivalent across all ages. However, young infants show memory retention for only a few days, whereas older infants show longer memory retention on a comparable train task. Importantly, at 6 mo of age, retention on these two operant tasks is equivalent. Based on data from Rovee-Collier (1999) and with permission of SAGE Publications (C) 1999. 
formed equivalent place memories. However, the ability to retain this information depended upon the age of the rats at the time of training. Whereas the youngest rats (18 d old, infants) showed rapid forgetting, rats that were $54 \mathrm{~d}$ old or older at the time of training (adults) showed perfect memory $42 \mathrm{~d}$ later (Fig. 3).

This core finding - that memory persistence is proportional to age at the time of training - has been replicated across a broad range of tasks, including conditioned suppression (Campbell and Campbell 1962), passive avoidance (Feigley and Spear 1970; Schulenburg et al. 1971; Campbell et al. 1974), active avoidance (Kirby 1963; Klein and Spear 1969; Campbell et al. 1974), appetitive discrimination (Campbell et al. 1968), contextual fear conditioning (Rudy and Morledge 1994; Weber et al. 2006), novel object recognition (Anderson et al. 2004), and water maze (Brown and Kraemer 1997). Importantly, each of these tasks uses stimuli with different properties and has different performance demands, indicating that this pattern of results is generalized across many memory tasks. Therefore, infantile amnesia is a robust, and very likely, universal cross-species phenomenon.

\section{Theories of infantile amnesia}

Why are memories acquired in infancy beyond recall in adulthood? This question has provoked much debate and a diverse range of theories have been put forward to explain this phenomenon. As these theories approach infantile amnesia from different research traditions, they are pitched at different levels of analyses (but are not necessarily mutually exclusive).

\section{Human cognitive/psychological theories}

Human psychological theories emphasize that the ability to form enduring memories (the offset of infantile amnesia) in humans coincides with emergence of developmental milestones, such as the acquisition of a sense of "self" (Howe and Courage 1993), theory of mind (Perner and Ruffman 1995), or language (Nelson 1993; Harley and Reese 1999; Simcock and Hayne 2002). Certainly, verbal reminiscing may aid memory retention, and the concept of self would help humans encode and store enduring personal memories. However, given that infantile amnesia is observed in nonhuman species, it is unlikely that this phenomenon can be explained fully using purely human concepts.

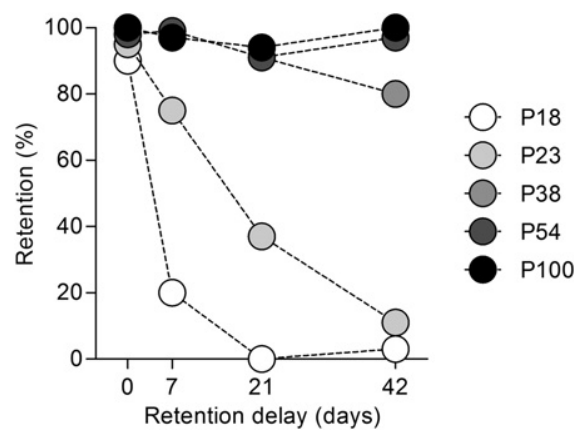

Figure 3. Infantile amnesia in rats. Rats trained at a young age (P18) show rapid forgetting, whereas as rats trained at later time points show much longer memory retention on an aversively motivated place discrimination task. Importantly, all rats (regardless of age at training) showed intact memory if tested immediately following training, indicating that rats of all ages formed equivalent place memories. Based on data (now in the public domain) from Campbell and Campbell (1962).

\section{Impairment in memory encoding, storage, or recall}

Information processing theories postulate that infantile amnesia results from impaired memory encoding, storage, and/or retrieval. Although it makes intuitive sense that if a normal memory is never acquired by an infant, then this memory cannot be recalled when the child reaches adulthood, experimental evidence from both human and rodent studies does not fully support this notion. For example, in the early infantile amnesia experiments in rats, both the rate of acquisition as well as initial memory expression (tested shortly after training) were equivalent in infant and adult rats (Kirby 1963; Feigley and Spear 1970; Campbell et al. 1974), suggesting that initial differences in learning and/or memory expression could not account for the accelerated forgetting observed in infant rats. Moreover, even when infant rats were overtrained in a passive avoidance task, they still showed more rapid forgetting than adult rats (Feigley and Spear 1970; Schulenburg et al. 1971).

Other explanations of infantile amnesia focus on memory retrieval and postulate that the memories formed in childhood are permanently stored and always exist, but that these memories simply cannot be accessed during adulthood (Hayne and RoveeCollier 1995). For instance, Freud believed that our earliest memories were acquired and stored in pristine condition but actively repressed due to their emotionally and sexually charged content (Freud 1899). In this way, Freud was perhaps the first (and strongest) proponent of the "memory retrieval deficit" hypothesis of infantile amnesia. Although Freud's notion of repression has been largely discounted, the retrieval deficit hypothesis of infantile amnesia is consistent with findings that memories are maximally recalled when the retrieval conditions (both internal and external) closely match the conditions at encoding, similar to state-dependency (Tulving and Thompson 1973; Tulving 1983). Because adults can never recapitulate the conditions of infancy, this theory holds, we cannot recall memories acquired during this time.

\section{Biological theories: the 'immature brain' vs. ‘ongoing brain maturation'}

Biological or neurological accounts of infantile amnesia stress two closely related ideas: either that infantile amnesia occurs because key structures for memory formation and storage are insufficiently mature at the time of memory formation to process these memories ("immature brain" theories) or, alternatively, that the very process of ongoing maturation interferes with stable memory consolidation ("ongoing brain maturation" theories). Support for these biological theories comes from findings that, although much of the human brain is fully formed at birth, the two key regions for declarative memory, the cortex and hippocampus, show protracted postnatal development (Eriksson et al. 1998; Knoth et al. 2010; Sierra et al. 2011). Some theories falling into the "immature brain" category posit infantile amnesia results from the cortex not yet being "online" in infants (Pillemer and White 1989; Nelson 1997, 2000). Indeed, although all six layers of the human cortex may be observed by the seventh gestational month, other important aspects of cortical maturity (e.g., adult levels of synaptic density, myelination, etc.) are not realized fully until puberty and beyond (Huttenlocher and Dabholkar 1997; Giedd et al. 1999; Bauer 2008). The rapid myelination that occurs in the first year in humans may account for the age-related changes in processing speed observed in several memory tasks (Richmond and Nelson 2007). That is, the finding that older infants encode some types of information faster than younger infants (e.g., Rose et al. 1982; Hayne 2004) might be due to faster information processing resulting from more efficient transmission of electrical impulses with increasing myelination. Whether changes in myelination (or other slowly maturing aspects of cortical integrity) are 
causally related to infantile amnesia, however, remains to be determined.

In addition to the cortex, the hippocampus, and especially the dentate gyrus (DG) region of the hippocampus, shows protracted postnatal development in many species, including humans (e.g., Eriksson et al. 1998; Knoth et al. 2010; Sierra et al. 2011). For instance, in humans, although the cytoarchitecture of the hippocampus is formed by 24-25 wk of gestation (Humphrey 1967; Seress et al. 2001) and the overall structure of the hippocampal formation largely resembles the adult by the end of the second trimester (Abraham et al. 2001), new neurons continue to be added to the DG layer of the hippocampus well after birth (Eriksson et al. 1998; Knoth et al. 2010; Sierra et al. 2011). Other "immature brain" theories suggest that this prolonged hippocampal development can account for infantile amnesia (Alvarado and Bachevalier 2000; Richmond and Nelson 2007). Indeed, the protracted development of the hippocampus, particularly the DG, after birth in monkeys is consistent with their emerging ability to form and retain episodiclike memories (Alvarado and Bachevalier 2000; Payne et al. 2010). For instance, although infant macaque monkeys (4 wk of age) show the ability to learn and form a memory (novelty preference) in the visual paired-comparison task (Gunderson and Sackett 1984; Gunderson and Swartz 1985; Bachevalier et al. 1993), memory stability gradually increases with age (from 1.5 to $18 \mathrm{mo}$ ) (Zeamer et al. 2010).

Distinct from these "immature brain" accounts are "ongoing brain maturation" accounts emphasizing that age-dependent/ontogenetic changes in memory persistence play out against a rapidly evolving brainscape, and it is the process of maturation itself (rather than the maturational state per se) that interferes with the storage of memories formed during infancy. For example:

"In the simplest sense, it seems quite possible that continued neurological development following the acquisition of a learned response could act to either disrupt the memorystorage mechanism(s) or to block retrieval of previously learned material." [Campbell and Spear 1972, p. 225; emphasis added.]

The key idea here is that, while memory formation is more or less normal in infants, continued brain maturation after initial acquisition may interfere with stabilization or consolidation of the memory trace. This hypothesis was initially examined in rodent studies where they either attempted to slow or accelerate brain maturation during the retention delay (reasoning that slowing maturation might counteract forgetting, whereas accelerating brain maturation might promote forgetting). The challenge for these early studies was that the tools available to manipulate brain maturation were blunt (e.g., hormonal or neurotoxic manipulations designed to slow or accelerate maturation likely had many off-target effects). Moreover, it was not clear whether specific or general aspects of maturation should be targeted. For the most part, these early attempts to manipulate brain maturation and examine infantile amnesia ended in failure (Campbell 1984).

Here, we propose that one specific aspect of ongoing brain maturation-the continued postnatal production of new neurons in the hippocampus-regulates the ability to form enduring hippocampus-dependent memories. As described above, in a variety of animals, including humans, new neurons continue to be added to the hippocampus, a brain region generally agreed to be important for memory. Interestingly, the levels of neurogenesis and memory stability are inversely related: The inability to form stable, persistent memories in early life coincides with a period of high neurogenesis, whereas the ability to form stable, persistent memories only emerges at later developmental periods as the rate of neurogenesis declines (Fig. 4). How might the addition of neu-

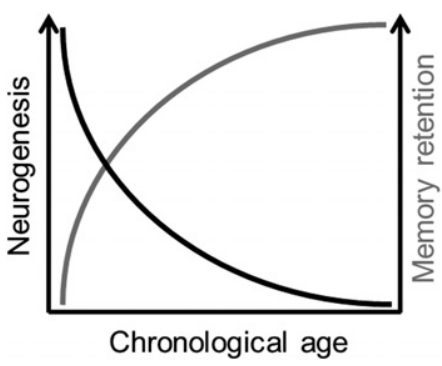

Figure 4. The neurogenic hypothesis of infantile amnesia. Levels of neurogenesis (black) and memory stability/retention (gray) are inversely related: The inability to form stable, persistent memories in early life coincides with a period of high neurogenesis, whereas the ability to form stable, persistent memories only emerges at later developmental periods as the rate of neurogenesis declines.

rons disrupt an established memory? We suggest that the integration of these "new neurons" degrades existing memories by either increasing the excitability (and therefore instability) of hippocampal memory networks or replacing synaptic connections in preexisting hippocampal memory circuits. This neurogenic hypothesis of infantile amnesia builds on the original ideas of Campbell and Spears (1972) and integrates contemporary views of how ongoing neurogenesis impacts hippocampal circuit function and information storage (Chambers et al. 2004; Deisseroth et al. 2004; Meltzer et al. 2005; Wiskott et al. 2006; Treves et al. 2008). Below, we review some existing evidence for this neurogenic hypothesis of infantile amnesia before outlining two direct tests of the hypothesis.

\section{Circumstantial evidence for the neurogenic hypothesis of infantile amnesia}

\section{Memory stability and neurogenesis are inversely related: As hippocampal neurogenesis declines, the ability to form stable memories emerges}

Whereas in most brain regions, neurogenesis is largely completed at birth, in the DG of the hippocampus, new neurons continue to be added throughout development into adulthood. Once controversial (Rakic 2002), the idea that neurogenesis may persist beyond birth is now accepted (Zhao et al. 2008). In the mammalian brain (including the human brain) (Eriksson et al. 1998; Knoth et al. 2010; Sierra et al. 2011), adult neurogenesis is limited to two regions: (1) the subventricular zone (SVZ) of the lateral ventricle (new neurons migrate from here along the rostral migratory stream to populate the olfactory bulb); and (2) the subgranular zone (SGZ) of the hippocampus (new neurons migrate the short distance from the SGZ to the inner granule cell layer [GCL] of the DG) (Zhao et al. 2008). Neurogenesis outside of these regions may occur following injury but is otherwise negligible under nonpathological conditions.

While postnatal hippocampal neurogenesis is regulated by a number of factors, it is most profoundly regulated by age (Seki and Arai 1995; Kuhn et al. 1996; Piatti et al. 2006): Across species, neuron production in the hippocampus typically peaks soon after birth and steadily declines thereafter. For example, in rats, the rate of hippocampal neurogenesis decreases by half between 1 and 2 mo of age, and by 18 mo of age, rates of neurogenesis are $\sim 100$-fold lower than initial levels (Seki and Arai 1995; Fig. 5A). Similarly, although most neurons in the nonhuman primate hippocampal formation are generated prenatally (Nowakowski and Rakic 1981; Eckenhoff and Rakic 1988; Arnold and Trojanowski 

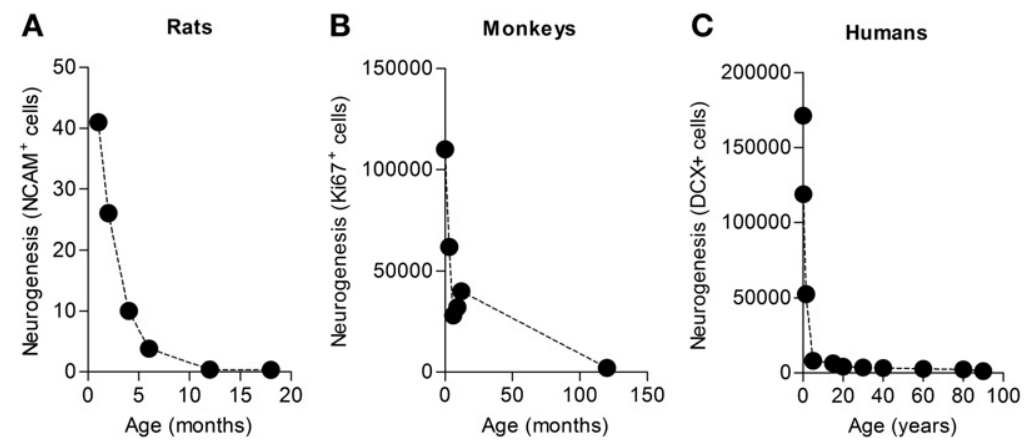

Figure 5. Rates of hippocampal neurogenesis decrease with age in both rats and humans. (A) In rats, the rate of hippocampal neurogenesis (as determined by the number of $\mathrm{NCAM}^{+}$cells) decreases by half between 1 and 2 mo of age, and by 18 mo of age, rates of neurogenesis are $\sim 100$-fold lower than initial levels (adapted from Seki and Arai 1995 with permission of Wolters Kluwer Health (C) 1995). A similar decay in hippocampal neurogenesis rate is observed in $(B)$ monkeys (determined by the number of Ki $67^{+}$cells) (adapted from Jabès et al. 2010 with permission of John Wiley and Sons (C) 2010) and (C) humans (determined by the number of doublecortin ${ }^{+}$cells) (Knoth et al. 2010).

( 21 d), precocial rodents (such as guinea pigs) have much longer gestation periods ( $\sim 65$ d) (Altman and Das 1967). Unlike rats, guinea pigs are able to walk and see at birth, suggesting that guinea pigs are born with a more developed brain. Consistent with this, whereas there is an $\sim 600 \%$ increase in brain weight from birth to full maturity in rats, the corresponding increase is only $\sim 60 \%$ in guinea pigs (Dobbing and Sands 1979). In landmark experiments, Campbell and colleagues asked whether the guinea pigs' relative neurological maturity at birth might be associated with a precocious ability to form persistent memories (Campbell et al. 1974). These researchers trained rats and guinea pigs of different ages in an aversively motivated place discrimination task and tested memory retention across a 2-wk period. Both young (15-20 d old at the time of train-

1996), postnatal neurogenesis is observed in the DG of macaque monkeys (Gould et al. 1999; Kornack and Rakic 1999) and marmosets (Gould et al. 1998). Recently, Jabès and colleagues (2010) systematically examined postnatal hippocampal neurogenesis across the life-span of macaques. Using both exogenous (BrdU) and endogenous (Ki67) markers of cell proliferation and stereological counting techniques, they found high levels of cell proliferation in the monkey DG at birth through 3 mo of life, followed by an intermediate level which persisted throughout the first year of life and beyond (Fig. 5B). Finally, although an equivalent systematic study of neurogenesis across the lifespan of humans has not been conducted, a similar decay in the rate of hippocampal neurogenesis is observed (Knoth et al. 2010). By staining post-mortem human brain tissue for doublecortin, a protein that is predominantly expressed in immature neurons, Knoth and colleagues (2010) estimated there is an $\sim 100$-fold reduction in neurogenesis between 0 and $100 \mathrm{yr}$ of age (Fig. 5C), a lifetime reduction in neurogenesis rates that is remarkably similar to that observed in rats as well as nonhuman primates.

These age-dependent changes in neurogenesis exhibit remarkably similar properties across species. For example, in the adult rat, the number of new neurons generated per day in the DG is roughly 2250 , or $0.2 \%$ of the total number of neurons in the granule cell layer (Cameron and McKay 2001). In 5- to 10 -yr-old (adult) monkeys, roughly 1300 neurons per day are added to the DG, or $0.02 \%$ of the total number of neurons in the granule cell layer. Given the differences in lifespan between monkeys and rats (the lifespan of a monkey is $\sim 20-30 \mathrm{yr}$ compared to $2-3$ $\mathrm{yr}$ for rats), the overall contribution of postnatal neurogenesis in these two species is remarkably similar. Indeed, Jabès and colleagues estimate that $\sim 40 \%$ of neurons are added to the monkey DG after birth. Together, these data suggest that postnatal neurogenesis could have a substantial impact on hippocampal circuit function in rodents and primates, including humans.

\section{Precocious guinea pigs do not show infantile amnesia}

That the decline in hippocampal neurogenesis levels in rats and primates coincides with an emerging ability to form enduring memories raises the fascinating possibility that these two phenomena are causally related. Although this has not been directly tested, there is some evidence from comparative studies of memory in different rodent species that strengthens this connection. Whereas altricial rodents (such as rats) have relatively brief gestation periods ing) and older (25-35 d old at the time of training) rats showed robust acquisition of this task and intact memory retention one day after training. However, younger rats showed forgetting across the 2-wk retention period compared to the stable retention observed in adult rats. In stark contrast, guinea pigs did not show an agedependent difference in memory persistence. Remarkably, 5-d-old guinea pigs remembered just as well as adult (100-d-old) guinea pigs up to $75 \mathrm{~d}$ after training (Fig. 6). A similar pattern of results was observed when memory retention was examined using passive avoidance (Campbell et al. 1974).

This difference in the ability of young rats and guinea pigs to form persistent memories directly mirrors differences in DG development between the two rodent species: Whereas $\sim 80 \%$ of granule cells are added to the DG in the first $2 \mathrm{wk}$ after birth in the rat, only $\sim 20 \%$ of granule cells are added during the first postnatal month in the guinea pig (Schlessinger et al. 1975; Guidi et al. 2005). Therefore, the relative maturity of the DG (and lower levels of neurogenesis) may permit the formation of stable memories in newborn guinea pigs. Of course, many other aspects of brain development both inside and outside of the hippocampus may also be more advanced at birth in guinea pigs (e.g., white matter, dendritic arborization, etc.), and it is possible these may also contribute to memory stability in newborn guinea pigs. Nonetheless, the lack of forgetting in newborn guinea pigs is consistent with the idea that lower levels of hippocampal neurogenesis facilitate memory persistence.

\section{Neurogenesis and degradation of existing memories: computational studies}

Although postnatal (including adult) hippocampal neurogenesis recapitulates many aspects of embryonic neurogenesis, postnatal neurogenesis is unique in that new neurons must integrate into an established hippocampal circuit. This integration may have profound effects on overall hippocampal circuit function. Experimental studies have predominantly focused on the anterograde effects of neurogenesis on memory-that is, examining the impact of manipulating neurogenesis levels on subsequent memory formation in adult animals (Shors et al. 2001; Creer et al. 2010; Deng et al. 2010; Sahay et al. 2011a). However, computational approaches have additionally emphasized the impact of adult neurogenesis on already-stored information (or retrograde effects) and proposed that the addition of new neurons may degrade 

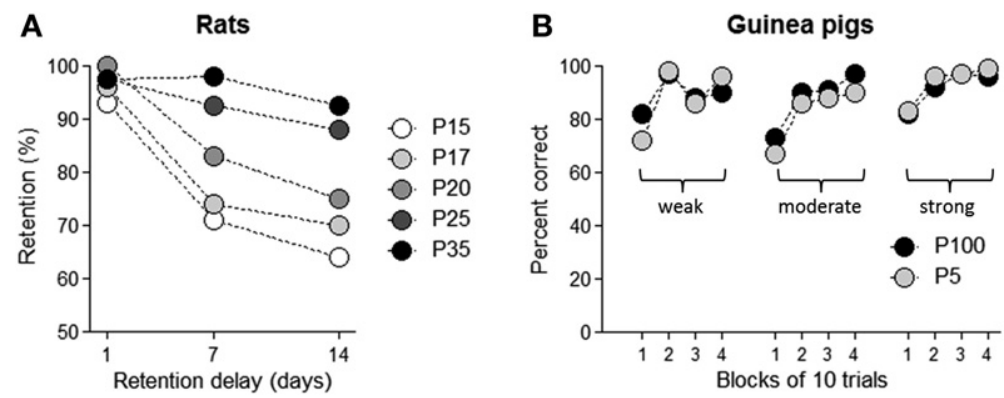

Figure 6. Cross-species evidence for the neurogenic hypothesis of infantile amnesia. (A) Altricial rodents (rats) with relatively brief gestation periods (and higher levels of postnatal neurogenesis) show evidence of infantile amnesia (younger rats forget sooner than older rats). (B) By contrast, precocial rodents (guinea pigs) have much longer gestation periods (and relatively lower levels of postnatal neurogenesis) and show no evidence of infantile amnesia. In fact, 5-d-old guinea pigs remembered just as well as adult (100-d-old) guinea pigs $75 \mathrm{~d}$ after either weak, moderate, or strong training in a place discrimination task. Adapted from Campbell et al. (1974).

existing memories (for review, see Aimone and Gage 2011). The idea that neurogenesis promotes memory degradation or forgetting echoes an earlier suggestion by Tsien and colleagues (Feng et al. 2001) and, when levels of hippocampal neurogenesis are considered across the lifespan, may explain the rapid forgetting of infantile amnesia.

These computational models typically use a simple, threelayer architecture (an input [entorhinal cortex], middle [DG], and output [CA3] layer), with neurogenesis modeled by either replacing mature neurons or adding new neurons to the middle DG layer (Chambers et al. 2004; Deisseroth et al. 2004; Meltzer et al. 2005; Wiskott et al. 2006). As mature dentate neurons constitute a critical component of the memory trace in these models, replacing these essential neurons (perhaps unsurprisingly) leads to memory degradation. However, results from experimental studies suggest that neurons that are committed to a memory trace may actually have a survival advantage (Leuner et al. 2004), suggesting that these mature memory-committed neurons are not likely to be replaced. Moreover, in some computational models, memory loss is still predicted when new neurons are simply added to the circuit, rather than replacing existing neurons (Deisseroth et al. 2004; Meltzer et al. 2005). This finding suggests that the integration of new neurons into an existing network may produce network-wide changes, leading to the degradation of already stored information. Consistent with this degradation hypothesis, decreasing adult hippocampal neurogenesis promotes, rather than disrupts, the long-lasting maintenance of hippocampal long-term potentiation in vivo (Kitamura et al. 2009).

There may be at least two ways in which adding new neurons might degrade existing memories. First, the integration of new neurons necessarily alters the wiring of existing hippocampal networks. As memory fidelity likely depends on the precise spatiotemporal activation of hippocampal neurons, any changes in network architecture would likely result in information loss. In this regard, it is particularly interesting that the formation of de novo afferent and efferent synaptic connections is a competitive process, with newborn neurons' synaptic connections frequently coexisting with, or even replacing, the synaptic connections of established neurons (Toni et al. 2007, 2008; Yasuda et al. 2011). Moreover, new neurons may have a competitive advantage over existing neurons in terms of afferent and efferent synaptic connections (Kim et al. 2011). Therefore, the invasion of new neurons into a preexisting circuit may disrupt the integrity of previously formed synapses, leading ultimately to the loss of stored information.
2001) or neuron-wide synaptic rescaling tosis of synaptic GluA2 receptors) (Frohlich et al. 2008; Turrigiano 2008), which may eventually lead to the silencing of some synapses, thus compromising information storage (Meltzer et al. 2005).

Are sufficient numbers of new neurons being added to the existing hippocampal circuit to impact the fidelity of stored memories? In young adult rodents, several thousand new neurons are generated daily (Cameron and McKay 2001). While not all of these new neurons survive, they still represent a sizable proportion of all dentate granule cells. For example, in the 3-mo-old rat, new neurons (defined as $<8$ wk of age) are estimated to make up $>25 \%$ of the entire granule cell population. This percentage drops with age, but even so, at $12 \mathrm{mo}$, new neurons likely account for 5\% of all dentate granule cells (Snyder and Cameron 2011). Each dentate granule cell contacts roughly 10-15 CA3 pyramidal neurons via large mossy fiber terminals (Acsady et al. 1998). These specialized contacts ensure powerful and reliable firing of downstream CA3 pyramidal neurons (Henze et al. 2002) and, therefore, even sparse activation of dentate granule cells can influence the activity of a large proportion of hippocampal CA3 neurons (Treves et al. 2008). In a similar vein, as new neurons integrate into hippocampal circuitry, they likely make contacts with a large number of CA3 target cells (in fact, adult-generated granule cells may even make more contacts on target CA3 neurons than granule cells generated earlier on during embryonic or postnatal development [Yasuda et al. 2011]). The establishment of these new synaptic connections necessarily alters the architecture of existing DG-CA3 networks, very likely leading to degradation (or loss) of information stored in those connections. It is, then, reasonable to predict that the amount of memory loss would depend on levels of hippocampal neurogenesis. When levels are high (during infancy), a larger proportion of DG-CA3 synapses would be impacted, leading to greater memory loss. In contrast, when neurogenesis levels are greatly reduced (during adulthood), fewer DG-CA3 synapses would be impacted by the integration of new neurons, resulting in greater memory stability.

\section{Neurogenesis and degradation of existing memories: experimental findings}

We hypothesize that memory instability in infants (infantile amnesia) is due to high levels of hippocampal neurogenesis. This hypothesis predicts that increasing levels of neurogenesis alone in adult animals would be sufficient to destabilize existing memories. Some indirect evidence for this prediction comes from the 
examination of mice that are deficient for the synaptic protein $\alpha$-calcium/calmodulin kinase II $\left(\alpha-\mathrm{CaMKII}^{+/-}\right.$mice) (Frankland et al. 2001, 2004; Yamasaki et al. 2008). In adult $\alpha$-CaMKII ${ }^{+/-}$ mice, there is a striking increase in the number of newborn neurons in the DG [adult mutant mice show 53\% more BrdU-labeled (newborn) cells in the DG, as well as higher levels of immature neuronal markers (PSA-NCAM or calretinin) compared with wild-type littermate mice]. Moreover, adult $\alpha$-CaMKII ${ }^{+/-}$ mice also show an electrophysiological DG profile typically observed in infant wild-type rodents (e.g., increased intrinsic excitability and membrane resistance, reduced spike amplitude and spike number during sustained depolarization [Yamasaki et al. 2008]). Interestingly, in these adult mice with high levels of hippocampal neurogenesis, memory stability is supremely compromised. Adult $\alpha$-CaMKII ${ }^{+/-}$mice are able to form new spatial and contextual memories, but memory retention is severely impaired (Frankland et al. 2001, 2004).

While these data are consistent with the idea that high levels of hippocampal neurogenesis promote forgetting, nonetheless, the $\alpha$-CaMKII mutation produces other alterations (e.g., impaired cortical plasticity [Frankland et al. 2001] and infradian activity patterns [Yamasaki et al. 2008]) that could also impair memory consolidation. Additional studies examined the impact of transiently increasing neurogenesis on the stability of an already formed memory in adult mice. For example, it is well-known that environmental enrichment robustly increases neurogenesis in adult rodents. However, this enhancement is attenuated in mice with a forebrain deletion of presenilin-1 (PS-1-deficient mice) (Feng et al. 2001). Consistent with the idea that there is a trade-off between levels of neurogenesis and memory stability, when PS-1-deficient mice and their wild-type littermates were environmentally enriched following training in a contextual fear task, PS-1-deficient mice (with lower levels of neurogenesis over the 1-mo retention delay) showed stronger memory than wildtype mice. Kitamura and colleagues reported a closely related finding (Kitamura et al. 2009). Voluntary exercise-which also robustly increases hippocampal neurogenesis in adult rodentsregulated the dependence of a contextual fear memory on the hippocampus. While expression of contextual fear memories initially depends on the hippocampus, a few weeks following training, context fear memory can be expressed independently of the hippocampus (Kim and Fanselow 1992; but see Nadel and Moscovitch 1997; Sutherland and Lehmann 2011). This shift from a hippocampus-dependent to hippocampus-independent memory appears to be accelerated when neurogenesis is increased (Kitamura et al. 2009), consistent with the idea that increased neurogenesis facilitates the clearance of the memory from the hippocampus. Therefore, together these studies provide some circumstantial support for the idea that integration of new granule cells into hippocampal circuitry may promote the degradation and/or clearance of existing information from the hippocampus (Feng et al. 2001; Deisseroth et al. 2004; Inokuchi 2011).

\section{Experimentally testing the neurogenic hypothesis of infantile amnesia}

The studies reviewed above provide indirect evidence for our neurogenic hypothesis of infantile amnesia. To more formally evaluate this hypothesis, we believe two types of experiments are critical (outlined below). The core manipulation in these experiments involves specifically increasing or decreasing levels of hippocampal neurogenesis in young and adult mice. Fortunately, increasingly sophisticated mouse-genetic approaches are beginning to make these targeted manipulations possible, while mini- mizing potential off-target effects (Dupret et al. 2008; Yu et al. 2008; Deng et al. 2009; Sahay et al. 2011b).

\section{Does increasing neurogenesis in adult animals after memory formation increase forgetting?}

\section{Making the hippocampus 'infantile' in an otherwise adult mouse}

Our hypothesis is that infants cannot form long-lasting memories because of high levels of neurogenesis, which promotes the degradation/clearance of memories soon after they are acquired. This hypothesis predicts that transiently increasing hippocampal neurogenesis after memory formation in adult mice will promote forgetting of newly acquired information (Fig. 7A). Key for this experiment is that the hippocampus only be transformed from an adult state-in which stable, persistent memories are formedto an infantile state-in which memories fade rapidly after formation. There are several methods that may be used to increase neurogenesis in adult mice, and these methods vary with respect to specificity. Some-such as environmental enrichment, voluntary exercise, and antidepressant treatment (Kempermann et al. 1997; van Praag et al. 1999; Malberg et al. 2000; Santarelli et al. 2003)_ are relatively nonspecific. In addition to increasing neurogenesis, these manipulations likely have a number of off-target effects. Others-such as electrical stimulation of hippocampal afferents (e.g., perforant path stimulation) (Bruel-Jungerman et al. 2006; Stone et al. 2011a) and, in particular, genetic or pharmacological inhibition of apoptotic cell death (Pieper et al. 2010; Sahay et al. 2011b)_likely increase neurogenesis while producing fewer offtarget effects. Interestingly, all of these manipulations typically increase adult hippocampal neurogenesis by roughly two- to threefold. In these experiments, it is important to evaluate the impact of increasing neurogenesis after memory formation on the subsequent stability of that memory (ensuring that initial encoding is not affected by the manipulation). We predict that (1) forgetting will be proportional to the duration and/or magnitude of increased neurogenesis, and (2) only hippocampus-dependent (and not hippocampus-independent) memories will be affected. Moreover, with time, some initially hippocampus-dependent memories may become hippocampus-independent (Frankland and Bontempi 2005; but see Nadel and Moscovitch 1997; Sutherland and Lehmann 2011). Therefore, we additionally predict that at remote time-points, initially hippocampus-dependent

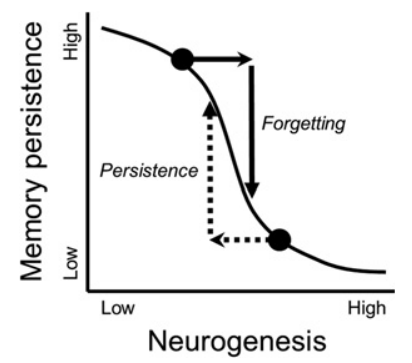

Figure 7. A test of the neurogenic hypothesis of infantile amnesia. Memory persistence is inversely correlated with levels of neurogenesis. Our hypothesis is that infants cannot form long-lasting memories because of high levels of neurogenesis, which promotes forgetting of recently acquired memories. We predict that making the hippocampus of an otherwise adult mouse "infantile" (increasing neurogenesis, solid black arrow) should promote forgetting of already acquired memories. On the other hand, making the hippocampus more "adult" in infant mice (decreasing neurogenesis, dotted black arrow) should promote memory persistence. 
memories likely become invulnerable to fluctuations in the rate of neurogenesis.

\section{Does decreasing neurogenesis in infant animals after memory formation decrease forgetting?}

\section{Making the hippocampus 'adult' in an otherwise juvenile mouse}

While a variety of evidence shows that infant rodents are able to form hippocampus-dependent memories, these memories do not persist and typically decay within days. If this instability is due to high rates of postnatal granule cell production, then we predict that suppressing neurogenesis will allow a young animal to form a stable, enduring (adult-like) memory (Fig. 7B). Transforming a juvenile hippocampus into an adult hippocampus is clearly a much tougher test of the hypothesis than increasing neurogenesis in adult rodents, as reducing neurogenesis at this early developmental stage might produce a range of off-target effects that may mask or compete with any pro-memory stability effects. Nonetheless, genetic, pharmacological, and irradiation-based approaches are available for suppressing neurogenesis, and there is a defined temporal window in which these manipulations could be applied. In the mouse and rat brain, neurogenesis is largely limited to the subgranular zone of the hippocampus and subventricular zone by $\sim 2$ wk following birth (and neurogenesis in these two regions alone persists into adulthood). Moreover, rodents $<3$ wk of age are typically unable to form stable hippocampus-dependent memories. Therefore, the neurogenic hypothesis of infantile amnesia could be tested by reducing neurogenesis after training in mice $<3 \mathrm{wk}$ of age to determine if memories are more persistent. Would such a manipulation completely rescue infantile amnesia? Factors other than hippocampal neurogenesis likely contribute to infantile amnesia. For example, the hippocampus interacts with a number of other structures (notably the cortex) during memory formation and maintenance. Therefore, protracted maturation of hippocampal-cortical connectivity or cortical structures for "permanent" storage (Alvarado and Bachevalier 2000; Richmond and Nelson 2007) may prevent complete rescue of infantile amnesia.

\section{Some final thoughts}

\section{Is adult neurogenesis good or bad for memory? A matter of timing}

The finding that neurogenesis persists into adulthood has generated a great deal of enthusiasm, centering on the idea that promoting this process would benefit memory (Aimone et al. 2011; Sahay et al. 2011a). Therefore, the suggestion that increasing neurogenesis in adult animals might actually destabilize existing hippocampus-dependent memories is, perhaps, counter-intuitive. Are these two ideas-that adult neurogenesis contributes to both memory degradation (Feng et al. 2001; Deisseroth et al. 2004) as well as storage (e.g., Shors 2008)—compatible? We believe they are and reflect the biphasic, maturation-dependent contribution of adult-generated neurons to hippocampal memory (Fig. 8). That is, the mnemonic effects of adding new neurons to the DG depend on timing.

The two phases of neurogenesis depend on the age of the adult-generated neurons. Shortly after they are born, newly generated granule cells migrate into the granule cell layer of the DG, and by $\sim 2$ wk they begin to make functional afferent and efferent connections (Zhao et al. 2006; Toni et al. 2007, 2008). It is the process of establishing new synaptic connections that alters the architecture of existing DG-CA3 networks, perhaps leading to degradation (or loss) of information already stored in those con-

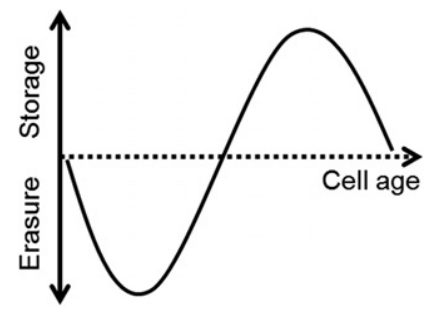

Figure 8. Adult neurogenesis and memory, a two-stage process. Adult neurogenesis contributes to both memory degradation/clearance (Feng et al. 2001; Deisseroth et al. 2004) as well as storage (e.g., Shors 2008), depending on the age of the cell. In the process of establishing new synaptic connections, new neurons alter the architecture of existing DG-CA3 networks, leading to degradation (or loss) of information stored in those connections. However, as these new neurons continue to mature, they enter the second phase where they acquire the potential to store memory and enhance memory storage.

nections. However, as these new neurons continue to mature, they enter the second phase in which they acquire the potential to store memory (or become part of the memory trace). For example, immediate early gene mapping studies suggest that adultgenerated neurons maximally contribute to hippocampal memory once they are four or more weeks in age (Kee et al. 2007; Stone et al. 2011b). Indeed, sufficiently mature adult-generated neurons have two key properties that may facilitate their ability to store memories. First, new neurons have "new" (silent?) synapses that may be specifically dedicated to storing new memories, and, second, new neurons are transiently more excitable and more plastic than their mature counterparts and, therefore, perhaps more readily incorporated into a memory trace.

\section{Out with the old...}

But why might memory degradation/clearance be adaptive? The pioneering memory researcher Théodule Ribot wrote that "forgetfulness, except in certain cases, is not a disease of memory, but a condition of its health and life" (Ribot 1882). Indeed, forgetting provides a mechanism for ridding the brain of unimportant information. Efficient forgetting, therefore, "unclutters" the hippocampus, allowing important new information to be more efficiently encoded (Martin et al. 2000; Altmann and Gray 2002; Schooler and Hertwig 2005). Such "adaptive" forgetting might facilitate the formation of new memories by simply increasing capacity (clearing space) and reducing interference between old, irrelevant memories and to-be-encoded information (Kraemer and Golding 1997; Wixted 2004). Indeed, the ability to block irrelevant information reduces the demands on the brain when trying to recall important information (Kuhl et al. 2007). Lifespan changes in levels of neurogenesis alter the balance between encoding and forgetting. During infancy, when neurogenesis levels are high, forgetting is favored, and so memories cannot endure. In late adulthood, when neurogenesis levels are low, insufficient clearance might lead to memory interference (i.e., too much unimportant information is retained). Sometime in between, there is a more optimal balance between encoding and forgetting.

Earlier models have proposed that the benefits of hippocampal neurogenesis-promoting activities (such as learning, exercise, or enrichment) are delayed (Kempermann 2008; Kim et al. 2011). That is, cells generated as a consequence of these types of activities (or the "neurogenic reserve") (Kempermann 2008) require sufficient time to differentiate into neurons, mature, and integrate into hippocampal circuitry before they promote memory function (Ge et al. 2007; Kee et al. 2007; Stone et al. 2011b). In contrast, we 
suggest that there are additional, more immediate benefits of increased neurogenesis. The integration of these new cells into hippocampal circuits may facilitate cognitive function by clearing older memories, reducing interference and increasing capacity.

\section{Acknowledgments}

This project was supported by CIHR grants to S.A.J. (MOP-74650) and P.W.F. (MOP-77561), as well as a "Chase an Idea in Paediatric Neuroscience" grant from The Centre for Brain \& Behaviour at the Hospital for Sick Children. We thank Katherine Akers, Alonso Martinez-Canabal, Leonardo Restivo, Anne Wheeler, and Stefan Köhler for helpful discussions throughout this project. We thank Leigh Botly for her expert help in preparing the figures.

\section{References}

Abraham H, Tornoczky T, Kosztolanyi G, Seress L. 2001. Cell formation in the cortical layers of the developing human cerebellum. Int J Dev Neurosci 19: 53-62.

Acsady L, Kamondi A, Sik A, Freund T, Buzsaki G. 1998. GABAergic cells are the major postsynaptic targets of mossy fibers in the rat hippocampus. J Neurosci 18: 3386-3403.

Aimone JB, Gage FH. 2011. Modeling new neuron function: A history of using computational neuroscience to study adult neurogenesis. Eur J Neurosci 33: 1160-1169.

Aimone JB, Deng W, Gage FH. 2011. Resolving new memories: A critical look at the dentate gyrus, adult neurogenesis, and pattern separation. Neuron 70: $589-596$.

Altman J, Das GD. 1967. Postnatal neurogenesis in the guinea-pig. Nature 214: $1098-1101$.

Altmann EM, Gray WD. 2002. Forgetting to remember: The functional relationship of decay and interference. Psychol Sci 13: 27-33.

Alvarado MC, Bachevalier J. 2000. Revisiting the maturation of medial temporal lobe memory functions in primates. Learn Mem 7: 244-256.

Anderson MJ, Barnes GW, Briggs JF, Ashton KM, Moody EW, Joynes RL, Riccio DC. 2004. Effects of ontogeny on performance of rats in a novel object-recognition task. Psychol Rep 94: 437-443.

Arnold SE, Trojanowski JQ. 1996. Human fetal hippocampal development: I. Cytoarchitecture, myeloarchitecture, and neuronal morphologic features. J Comp Neurol 367: 274-292.

Bachevalier J, Brickson M, Hagger C. 1993. Limbic-dependent recognition memory in monkeys develops early in infancy. Neuroreport 4: 77-80.

Barr R, Dowden A, Hayne H. 1996. Developmental change in deferred imitation by 6- to 24-month-old infants. Infant Behav Dev 19: 159-170.

Bauer PJ. 2006. Constructing a past in infancy: A neuro-developmental account. Trends Cogn Sci 10: 175-181.

Bauer PJ. 2007. Remembering the times of our lives: Memory in infancy and beyond. Lawrence Erlbaum Associates, Mahwah, NJ.

Bauer PJ. 2008. Toward a neuro-developmental account of the development of declarative memory. Dev Psychobiol 50: 19-31.

Brickley SG, Revilla V, Cull-Candy SG, Wisden W, Farrant M. 2001. Adaptive regulation of neuronal excitability by a voltage-independent potassium conductance. Nature 409: 88-92.

Brown RW, Kraemer PJ. 1997. Ontogenetic differences in retention of spatial learning tested with the Morris water maze. Dev Psychobiol 30: $329-341$.

Bruce D, Wilcox-O'Hearn LA, Robinson JA, Phillips-Grant K, Francis L, Smith MC. 2005. Fragment memories mark the end of childhood amnesia. Mem Cognit 33: 567-576.

Bruel-Jungerman E, Davis S, Rampon C, Laroche S. 2006. Long-term potentiation enhances neurogenesis in the adult dentate gyrus. J Neurosci 26: $5888-5893$.

Cameron HA, McKay RD. 2001. Adult neurogenesis produces a large pool of new granule cells in the dentate gyrus. J Comp Neurol 435: 406-417.

Campbell BA. 1984. Reflections on the ontogeny of learning and memory. In Comparative perspectives on the development of memory (ed. RV Kail, NE Spear), pp. 23-35. Routledge, New York, NY.

Campbell BA, Campbell EH. 1962. Retention and extinction of learned fear in infant and adult rats. J Comp Physiol Psychol 55: 1-8.

Campbell BA, Spear NE. 1972. Ontogeny of memory. Psychol Rev 79: $215-236$.

Campbell BA, Jaynes J, Misanin JR. 1968. Retention of a light-dark discrimination in rats of different ages. J Comp Physiol Psychol 66: 467-472.

Campbell BA, Misanin JR, White BC, Lytle LD. 1974. Species differences in ontogeny of memory: Indirect support for neural maturation as a determinant of forgetting. J Comp Physiol Psychol 87: 193-202.
Carver LJ, Bauer PJ. 2001. The dawning of a past: The emergence of long-term explicit memory in infancy. J Exp Psychol Gen 130: 726-745. Chambers RA, Potenza MN, Hoffman RE, Miranker W. 2004. Simulated apoptosis/neurogenesis regulates learning and memory capabilities of adaptive neural networks. Neuropsychopharmacology 29: 747-758

Coulter X, Collier AC, Campbell BA. 1976. Long-term retention of early Pavlovian fear conditioning in infant rats. J Exp Psychol Anim Behav Process 2: 48-56.

Creer DJ, Romberg C, Saksida LM, van Praag H, Bussey TJ. 2010. Running enhances spatial pattern separation in mice. Proc Natl Acad Sci 107: $2367-2372$.

Deisseroth K, Singla S, Toda H, Monje M, Palmer TD, Malenka RC. 2004. Excitation-neurogenesis coupling in adult neural stem/progenitor cells. Neuron 42: $535-552$.

Deng W, Saxe MD, Gallina IS, Gage FH. 2009. Adult-born hippocampal dentate granule cells undergoing maturation modulate learning and memory in the brain. J Neurosci 29: 13532-13542.

Deng W, Aimone JB, Gage FH. 2010. New neurons and new memories: How does adult hippocampal neurogenesis affect learning and memory? Nat Rev Neurosci 11: 339-350.

Desai NS, Rutherford LC, Turrigiano GG. 1999. Plasticity in the intrinsic excitability of cortical pyramidal neurons. Nat Neurosci 2: 515-520.

Dobbing J, Sands J. 1979. Comparative aspects of the brain growth spurt. Early Hum Dev 3: 79-83.

Dupret D, Revest JM, Koehl M, Ichas F, De Giorgi F, Costet P, Abrous DN, Piazza PV. 2008. Spatial relational memory requires hippocampal adult neurogenesis. PLoS One 3: e1959. doi: 10.1371/journal.pone.0001959.

Eckenhoff MF, Rakic P. 1988. Nature and fate of proliferative cells in the hippocampal dentate gyrus during the life span of the rhesus monkey. J Neurosci 8: 2729-2747.

Eisenberg A. 1985. Learning to describe past experience in conversation. Discourse Process 8: 177-204.

Eriksson PS, Perfilieva E, Bjork-Eriksson T, Alborn AM, Nordborg C, Peterson DA, Gage FH. 1998. Neurogenesis in the adult human hippocampus. Nat Med 4: 1313-1317.

Fantz RL. 1956. A method of studying early visual development. Percept Mot Skills 6: $13-15$

Feigley DA, Spear NE. 1970. Effect of age and punishment condition on long-term retention by the rat of active- and passive-avoidance learning. J Comp Physiol Psychol 73: 515-526.

Feng R, Rampon C, Tang YP, Shrom D, Jin J, Kyin M, Sopher B, Miller MW, Ware CB, Martin GM, et al. 2001. Deficient neurogenesis in forebrain-specific presenilin-1 knockout mice is associated with reduced clearance of hippocampal memory traces. Neuron 32: 911-926.

Frankland PW, Bontempi B. 2005. The organization of recent and remote memories. Nat Rev Neurosci 6: 119-130.

Frankland PW, O'Brien C, Ohno M, Kirkwood A, Silva AJ. 2001. Alpha-CaMKII-dependent plasticity in the cortex is required for permanent memory. Nature 411: 309-313.

Frankland PW, Bontempi B, Talton LE, Kaczmarek L, Silva AJ. 2004. The involvement of the anterior cingulate cortex in remote contextual fear memory. Science 304: 881-883.

Freud S. 1899. The standard edition of the complete works of Sigmund Freud. Hogarth Press, London.

Freud S. 1900. The interpretation of dreams. Macmillan, New York, NY.

Freud S. 1914. Psychopathology of everyday life. The Macmillan Company, New York, NY.

Frohlich F, Bazhenov M, Sejnowski TJ. 2008. Pathological effect of homeostatic synaptic scaling on network dynamics in diseases of the cortex. J Neurosci 28: 1709-1720.

Ge S, Yang CH, Hsu KS, Ming GL, Song H. 2007. A critical period for enhanced synaptic plasticity in newly generated neurons of the adult brain. Neuron 54: 559-566.

Giedd JN, Blumenthal J, Jeffries NO, Castellanos FX, Liu H, Zijdenbos A, Paus T, Evans AC, Rapoport JL. 1999. Brain development during childhood and adolescence: A longitudinal MRI study. Nat Neurosci 2: 861-863.

Golowasch J, Abbott LF, Marder E. 1999. Activity-dependent regulation of potassium currents in an identified neuron of the stomatogastric ganglion of the crab. Cancer borealis. J Neurosci 19: RC33.

Gould E, Tanapat P, McEwen BS, Flugge G, Fuchs E. 1998. Proliferation of granule cell precursors in the dentate gyrus of adult monkeys is diminished by stress. Proc Natl Acad Sci 95: 3168-3171.

Gould E, Reeves AJ, Fallah M, Tanapat P, Gross CG, Fuchs E. 1999. Hippocampal neurogenesis in adult Old World primates. Proc Natl Acad Sci 96: 5263-5267.

Graf P, Schacter DL. 1985. Implicit and explicit memory for new associations in normal and amnesic subjects. J Exp Psychol Learn Mem Cogn 11: 501-518.

Guidi S, Ciani E, Severi S, Contestabile A, Bartesaghi R. 2005. Postnatal neurogenesis in the dentate gyrus of the guinea pig. Hippocampus 15: 285-301. 
Gunderson VM, Sackett GP. 1984. Development of pattern recognition in infant pigtailed macaques (Macaca nemestrina). Dev Psych 20: $418-426$.

Gunderson EP, Swartz K. 1985. Visual recognition in infant pigtailed macaques after a 24-hour delay. Am J Prim 8: 259-264.

Hackman DA, Farah MJ, Meaney MJ. 2010. Socioeconomic status and the brain: Mechanistic insights from human and animal research. Nat Rev Neurosci 11: 651-659.

Harley K, Reese E. 1999. Origins of autobiographical memory. Dev Psychol 35: $1338-1348$.

Hayne H. 2004. Infant memory development: Implications for childhood amnesia. Dev Rev 24: 33-73.

Hayne H, Rovee-Collier C. 1995. The organization of reactivated memory in infancy. Child Dev 66: 893-906.

Henri V, Henri C. 1895. On our earliest recollections of childhood. Am J Psychol 7: 303-304.

Henze DA, Wittner L, Buzsaki G. 2002. Single granule cells reliably discharge targets in the hippocampal CA3 network in vivo. Nat Neurosci 5: 790-795.

Herbert J, Hayne H. 2000. The ontogeny of long-term retention during the second year of life. Dev Sci 3: 50-56.

Howe ML, Courage ML. 1993. On resolving the enigma of infantile amnesia. Psychol Bull 113: 305-326.

Hudson JA. 1991. Learning to reminisce: A case study. Journal of Narrative and Life History 1: 1-32.

Hudson JA, Fivush R, Kuebli J. 1992. Scripts and episode: The development of event memory. Appl Cogn Psychol 6: 483-505.

Hudson JA, Shapiro LR, Sosa BB. 1995. Planning in the real world: Preschool children's scripts and plans for familiar events. Child Dev 66: 984-998.

Humphrey T. 1967. The development of the human hippocampal fissure. J Anat 101: 655-676.

Huttenlocher PR, Dabholkar AS. 1997. Regional differences in synaptogenesis in human cerebral cortex. J Comp Neurol 387: 167-178.

Inokuchi K. 2011. Adult neurogenesis and modulation of neural circuit function. Curr Opin Neurobiol 21: 360-364.

Jabès A, Lavenex PB, Amaral DG, Lavenex P. 2010. Quantitative analysis of postnatal neurogenesis and neuron number in the macaque monkey dentate gyrus. Eur J Neurosci 31: 273-285.

Karmarkar UR, Buonomano DV. 2006. Different forms of homeostatic plasticity are engaged with distinct temporal profiles. Eur J Neurosci 23: $1575-1584$.

Kee N, Teixeira CM, Wang AH, Frankland PW. 2007. Preferential incorporation of adult-generated granule cells into spatial memory networks in the dentate gyrus. Nat Neurosci 10: $355-362$.

Kempermann G. 2008. The neurogenic reserve hypothesis: What is adult hippocampal neurogenesis good for? Trends Neurosci 31: 163-169.

Kempermann G, Kuhn HG, Gage FH. 1997. More hippocampal neurons in adult mice living in an enriched environment. Nature 386: 493-495.

Kim JJ, Fanselow MS. 1992. Modality-specific retrograde amnesia of fear. Science 256: 675-677.

Kim WR, Christian K, Ming GL, Song H. 2011. Time-dependent involvement of adult-born dentate granule cells in behavior. Behav Brain Res 227: 470-479.

Kirby RH. 1963. Acquisition, extinction, and retention of an avoidance response in rats as a function of age. J Comp Physiol Psychol 56: 158-162.

Kitamura T, Saitoh Y, Takashima N, Murayama A, Niibori Y, Ageta H, Sekiguchi M, Sugiyama H, Inokuchi K. 2009. Adult neurogenesis modulates the hippocampus-dependent period of associative fear memory. Cell 139: 814-827.

Klein SB, Spear NE. 1969. Influence of age on short-term retention of active-avoidance learning in rats. J Comp Physiol Psychol 69: 583-589.

Knoth R, Singec I, Ditter M, Pantazis G, Capetian P, Meyer RP, Horvat V, Volk B, Kempermann G. 2010. Murine features of neurogenesis in the human hippocampus across the lifespan from 0 to 100 years. PLoS One 5: e8809. doi: 10.1371/journal.pone.0008809.

Kornack DR, Rakic P. 1999. Continuation of neurogenesis in the hippocampus of the adult macaque monkey. Proc Natl Acad Sci 96: $5768-5773$.

Kraemer PJ, Golding JM. 1997. Adaptive forgetting in animals. Psychon Bull Rev 4: 480-491.

Kuhl BA, Dudukovic NM, Kahn I, Wagner AD. 2007. Decreased demands on cognitive control reveal the neural processing benefits of forgetting. Nat Neurosci 10: 908-914.

Kuhn HG, Dickinson-Anson H, Gage FH. 1996. Neurogenesis in the dentate gyrus of the adult rat: Age-related decrease of neuronal progenitor proliferation. J Neurosci 16: 2027-2033.

Leuner B, Mendolia-Loffredo S, Kozorovitskiy Y, Samburg D, Gould E, Shors TJ. 2004. Learning enhances the survival of new neurons beyond the time when the hippocampus is required for memory. J Neurosci 24: 7477-7481.
Malberg JE, Eisch AJ, Nestler EJ, Duman RS. 2000. Chronic antidepressant treatment increases neurogenesis in adult rat hippocampus. J Neurosci 20: $9104-9110$.

Martin SJ, Grimwood PD, Morris RG. 2000. Synaptic plasticity and memory: An evaluation of the hypothesis. Annu Rev Neurosci 23: 649-711.

McCabe A, Peterson C. 1991. Getting the story: A longitudinal study of parental styles in eliciting narratives and developing narrative skill. In Developing narrative structure (ed. A McCabe, C Peterson), pp. 217-253. Lawrence Erlbaum Associates, Hillsdale, NJ.

Meltzer LA, Yabaluri R, Deisseroth K. 2005. A role for circuit homeostasis in adult neurogenesis. Trends Neurosci 28: 653-660.

Miles C. 1893. A study of individual psychology. Am J Psychol 6: 534-558.

Miller PJ, Sperry LL. 1988. Early talk about the past: The origins of conversational stories of personal experience. J Child Lang 15: 293-315.

Morgan K, Hayne H. 2006a. Age-related changes in memory reactivation by 1- and 2-year-old human infants. Dev Psychobiol 48: 48-57.

Morgan K, Hayne H. 2006b. The effect of encoding time on retention by infants and young children. Infant Behav Dev 29: 599-602.

Morgan K, Hayne H. 2011. Age-related changes in visual recognition memory during infancy and early childhood. Dev Psychobiol 53: $157-165$.

Nadel L, Moscovitch M. 1997. Memory consolidation, retrograde amnesia and the hippocampal complex. Curr Opin Neurobiol 7: 217-227.

Nelson K. 1989. Narratives from the crib. Harvard University Press, Cambridge, MA.

Nelson K. 1993. The psychological and social origins of autobiographical memory. Psychol Sci 4: 7-14.

Nelson CA. 1997. The neurobiological basis of early memory development. In The development of memory in early childhood (ed. N Cowan), pp. 41-82. Psychology Press, Hove, East Sussex, UK.

Nelson CA. 2000. Neural plasticity in human development: The role of early experience in sculpting memory systems. Dev Sci 3: $115-130$.

Nelson K, Fivush R. 2004. The emergence of autobiographical memory: A social cultural developmental theory. Psychol Rev 111: 486-511.

Nelson K, Gruendel J. 1981. Generalized event representations: Basic building blocks of cognitive development. In Advances in developmental psychology (ed. ME Lamb, AL Brown), pp. 131-158. Lawrence Erlbaum Associates, Hillsdale, NJ.

Nowakowski RS, Rakic P. 1981. The site of origin and route and rate of migration of neurons to the hippocampal region of the rhesus monkey. J Comp Neurol 196: 129-154.

Ornstein PA, Baker-Ward L, Gordon BN, Merritt KA. 1997. Children's memory for medical experiences: Implications for testimony. Appl Cogn Psychol 11: 87-104.

Payne C, Machado CJ, Bliwise NG, Bachevalier J. 2010. Maturation of the hippocampal formation and amygdala in Macaca mulatta: A volumetric magnetic resonance imaging study. Hippocampus 20: 922-935.

Perner J, Ruffman T. 1995. Episodic memory and autonoetic consciousness: Developmental evidence and a theory of childhood amnesia. J Exp Child Psychol 59: 516-548.

Peterson C. 2002. Children's long-term memory for autobiographical events. Dev Rev 22: 370-402.

Peterson C, McCabe A. 1987. The connective 'and': Do older children use it less as they learn other connectives? J Child Lang 14: 375-381.

Peterson C, Jesso B, McCabe A. 1999. Encouraging narratives in preschoolers: An intervention study. J Child Lang 26: 49-67.

Piatti VC, Esposito MS, Schinder AF. 2006. The timing of neuronal development in adult hippocampal neurogenesis. Neuroscientist 12: $463-468$.

Pieper AA, Xie S, Capota E, Estill SJ, Zhong J, Long JM, Becker GL, Huntington P, Goldman SE, Shen CH, et al. 2010. Discovery of a proneurogenic, neuroprotective chemical. Cell 142: 39-51.

Pillemer DB, White SH. 1989. Childhood events recalled by children and adults. Adv Child Dev Behav 21: 297-340.

Rakic P. 2002. Adult neurogenesis in mammals: An identity crisis. J Neurosci 22: 614-618.

Ribot T. 1882. Diseases of memory. Appleton, New York, NY.

Richmond J, Nelson CA. 2007. Accounting for change in declarative memory: A cognitive neuroscience perspective. Dev Rev 27: 349-373.

Rose S, Gottfried A, Melloy-Carminar P, Bridger W. 1982. Familiarity and novelty preferences in infant recognition memory: Implications for information processing. Dev Psych 18: 704-713.

Rovee-Collier C. 1997. Dissociations in infant memory: Rethinking the development of implicit and explicit memory. Psychol Rev 104: 467-498.

Rovee-Collier C. 1999. The development of infant memory. Curr Dir Psychol Sci 8: 80-85.

Rovee-Collier C, Cuevas K. 2009. Multiple memory systems are unnecessary to account for infant memory development: An ecological model. Dev Psychol 45: 160-174. 
Rubin DC. 1982. On the retention function for autobiographical memory. Journal of Verbal Learning and Verbal Behavior 21: 21-38.

Rubin DC. 2000. The distribution of early childhood memories. Memory 8: $265-269$.

Rubin DC, Schulkind MD. 1997. The distribution of important and word-cued autobiographical memories in 20-, 35- and 70-year old adults. Psychol Aging 12: 524-535.

Rudy JW, Morledge P. 1994. Ontogeny of contextual fear conditioning in rats: Implications for consolidation, infantile amnesia, and hippocampal system function. Behav Neurosci 108: 227-234.

Sahay A, Wilson DA, Hen R. 2011a. Pattern separation: A common function for new neurons in hippocampus and olfactory bulb. Neuron 70: $582-588$.

Sahay A, Scobie KN, Hill AS, O'Carroll CM, Kheirbek MA, Burghardt NS, Fenton AA, Dranovsky A, Hen R. 2011b. Increasing adult hippocampal neurogenesis is sufficient to improve pattern separation. Nature 472: $466-470$.

Santarelli L, Saxe M, Gross C, Surget A, Battaglia F, Dulawa S, Weisstaub N, Lee J, Duman R, Arancio O, et al. 2003. Requirement of hippocampal neurogenesis for the behavioral effects of antidepressants. Science 301: 805-809.

Schlessinger AR, Cowan WM, Gottlieb DI. 1975. An autoradiographic study of the time of origin and the pattern of granule cell migration in the dentate gyrus of the rat. J Comp Neurol 159: 149-175.

Schmidt-Hieber C, Jonas P, Bischofberger J. 2004. Enhanced synaptic plasticity in newly generated granule cells of the adult hippocampus. Nature 429: 184-187.

Schooler LJ, Hertwig R. 2005. How forgetting aids heuristic inference. Psychol Rev 112: 610-628.

Schulenburg CJ, Riccio DC, Stikes ER. 1971. Acquisition and retention of a passive-avoidance response as a function of age in rats. J Comp Physiol Psychol 74: 75-83.

Seki T, Arai Y. 1995. Age-related production of new granule cells in the adult dentate gyrus. Neuroreport 6: 2479-2482.

Seress L, Abraham H, Tornoczky T, Kosztolanyi G. 2001. Cell formation in the human hippocampal formation from mid-gestation to the late postnatal period. Neuroscience 105: 831-843.

Shors TJ. 2008. From stem cells to grandmother cells: How neurogenesis relates to learning and memory. Cell Stem Cell 3: 253-258.

Shors TJ, Miesegaes G, Beylin A, Zhao M, Rydel T, Gould E. 2001. Neurogenesis in the adult is involved in the formation of trace memories. Nature 410: $372-376$.

Sierra A, Encinas JM, Maletic-Savatic M. 2011. Adult human neurogenesis: From microscopy to magnetic resonance imaging. Front Neurosci 5: 47.

Simcock G, Hayne H. 2002. Breaking the barrier? Children fail to translate their preverbal memories into language. Psychol Sci 13: 225-231.

Snyder JS, Cameron HA. 2011. Could adult hippocampal neurogenesis be relevant for human behavior? Behav Brain Res 227: 384-390.

Squire LR. 1994. Declarative and nondeclarative memory: Multiple brain systems supporting learning \& memory. In Memory systems (ed. DL Schacter, E Tulving), pp. 203-232. MIT Press, Cambridge, MA.

Stehouwer DJ, Campbell BA. 1980. Ontogeny of passive avoidance: Role of task demands and development of species-typical behaviors. Dev Psychobiol 13: 385-398.

Stone SS, Teixeira CM, Devito LM, Zaslavsky K, Josselyn SA, Lozano AM, Frankland PW. 2011a. Stimulation of entorhinal cortex promotes adult neurogenesis and facilitates spatial memory. J Neurosci 31: $13469-13484$.

Stone SS, Teixeira CM, Zaslavsky K, Wheeler AL, Martinez-Canabal A, Wang AH, Sakaguchi M, Lozano AM, Frankland PW. 2011b. Functional convergence of developmentally and adult-generated granule cells in dentate gyrus circuits supporting hippocampus-dependent memory. Hippocampus 21: $1348-1362$.

Sutherland RJ, Lehmann H. 2011. Alternative conceptions of memory consolidation and the role of the hippocampus at the systems level in rodents. Curr Opin Neurobiol 21: 446-451.

Toni N, Teng EM, Bushong EA, Aimone JB, Zhao C, Consiglio A, van Praag H, Martone ME, Ellisman MH, Gage FH. 2007. Synapse formation on neurons born in the adult hippocampus. Nat Neurosci 10: $727-734$.

Toni N, Laplagne DA, Zhao C, Lombardi G, Ribak CE, Gage FH, Schinder AF. 2008. Neurons born in the adult dentate gyrus form functional synapses with target cells. Nat Neurosci 11: 901-907.

Treves A, Tashiro A, Witter ME, Moser EI. 2008. What is the mammalian dentate gyrus good for? Neuroscience 154: 1155-1172.

Tulving E. 1983. Elements of episodic memory. Oxford University Press, New York, NY.

Tulving E, Thompson DM. 1973. Encoding specificity and retrieval processes in episodic memory. Psychol Rev 80: 352-373.

Turrigiano GG. 2008. The self-tuning neuron: Synaptic scaling of excitatory synapses. Cell 135: 422-435.

Tustin K, Hayne H. 2010. Defining the boundary: Age-related changes in childhood amnesia. Dev Psychol 46: 1049-1061.

van Abbema DL, Bauer PJ. 2005. Autobiographical memory in childhood: Development of a personal past. Memory 13: 829-845.

van Praag H, Kempermann G, Gage FH. 1999. Running increases cell proliferation and neurogenesis in the adult mouse dentate gyrus. Nat Neurosci 2: 266-270.

Wang Q. 2003. Infantile amnesia reconsidered: A cross-cultural analysis. Memory 11: 65-80.

Weber M, McNally GP, Richardson R. 2006. Opioid receptors regulate retrieval of infant fear memories: Effects of naloxone on infantile amnesia. Behav Neurosci 120: 702-709.

Wetzler SE, Sweeney JA. 1986. Childhood amnesia: An empirical demonstration. In Autobiographical memory (ed. DC Rubin), pp. 191-201. Cambridge University Press, New York, NY.

Wiskott L, Rasch MJ, Kempermann G. 2006. A functional hypothesis for adult hippocampal neurogenesis: Avoidance of catastrophic interference in the dentate gyrus. Hippocampus 16: 329-343.

Wixted JT. 2004. The psychology and neuroscience of forgetting. Annu Rev Psychol 55: 235-269.

Yamasaki N, Maekawa M, Kobayashi K, Kajii Y, Maeda J, Soma M, Takao K, Tanda K, Ohira K, Toyama K, et al. 2008. Alpha-CaMKII deficiency causes immature dentate gyrus, a novel candidate endophenotype of psychiatric disorders. Mol Brain 1: 6. doi: 10.1186/ 1756-6606-1-6.

Yasuda M, Johnson-Venkatesh EM, Zhang H, Parent JM, Sutton MA, Umemori H. 2011. Multiple forms of activity-dependent competition refine hippocampal circuits in vivo. Neuron 70: 1128-1142.

Yu TS, Zhang G, Liebl DJ, Kernie SG. 2008. Traumatic brain injury-induced hippocampal neurogenesis requires activation of early nestin-expressing progenitors. J Neurosci 28: 12901-12912.

Zeamer A, Heuer E, Bachevalier J. 2010. Developmental trajectory of object recognition memory in infant rhesus macaques with and without neonatal hippocampal lesions. J Neurosci 30: 9157-9165.

Zhao C, Teng EM, Summers RG Jr, Ming GL, Gage FH. 2006. Distinct morphological stages of dentate granule neuron maturation in the adult mouse hippocampus. J Neurosci 26: 3-11.

Zhao C, Deng W, Gage FH. 2008. Mechanisms and functional implications of adult neurogenesis. Cell 132: 645-660.

Received January 10, 2012; accepted in revised form May 2, 2012. 


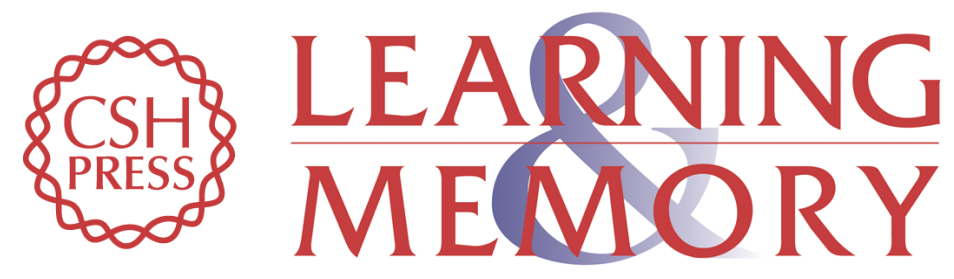

\section{Infantile amnesia: A neurogenic hypothesis}

Sheena A. Josselyn and Paul W. Frankland

Learn. Mem. 2012, 19:

Access the most recent version at doi:10.1101//m.021311.110

References This article cites 149 articles, 22 of which can be accessed free at: http://learnmem.cshlp.org/content/19/9/423.full.html\#ref-list-1

License

Email Alerting Receive free email alerts when new articles cite this article - sign up in the box at the Service top right corner of the article or click here. 